Article

\title{
Dereplication by High-Performance Liquid Chromatography (HPLC) with Quadrupole-Time-of-Flight Mass Spectroscopy (qTOF-MS) and Antiviral Activities of Phlorotannins from Ecklonia cava
}

\author{
Hyo Moon Cho ${ }^{1,+}$, Thi Phuong Doan ${ }^{1,+}$, Thi Kim Quy Ha ${ }^{1}$, Hyun Woo Kim ${ }^{1}$, Ba Wool Lee ${ }^{1}$, \\ Ha Thanh Tung Pham ${ }^{1}$, Tae Oh Cho ${ }^{2}$ and Won Keun $\mathrm{Oh}^{1, *(D)}$ \\ 1 Korea Bioactive Natural Material Bank, Research Institute of Pharmaceutical Sciences, College of Pharmacy, \\ Seoul National University, Seoul 08826, Korea; chgyans@naver.com (H.M.C.); \\ phuongdoan@snu.ac.kr (T.P.D.); htkquy@ctu.edu.vn (T.K.Q.H.); kimkami2@snu.ac.kr (H.W.K.); \\ paul36@snu.ac.kr (B.W.L.); thtungdl@gmail.com (H.T.T.P.) \\ 2 Marine Bio Research Center, Department of Life Science, Chosun University, Gwangju 501-759, Korea; \\ tocho@chosun.ac.kr \\ * Correspondence: wkoh1@snu.ac.kr; Tel.: +82-02-880-7872 \\ + These authors contributed equally.
}

Received: 31 January 2019; Accepted: 26 February 2019; Published: 4 March 2019

\begin{abstract}
Ecklonia cava is edible seaweed that is found in Asian countries, such as Japan and Korea; and, its major components include fucoidan and phlorotannins. Phlorotannins that are isolated from E. cava are well-known to have an antioxidant effect and strong antiviral activity against porcine epidemic diarrhea virus (PEDV), which has a high mortality rate in piglets. In this study, the bioactive components were determined based on two different approaches: (i) bio-guided isolation using the antiviral activity against the H1N1 viral strain, which is a representative influenza virus that originates from swine and (ii) high-resolution mass spectrometry-based dereplication, including relative mass defects (RMDs) and HPLC-qTOFMS fragmentation analysis. The EC70 fraction showed the strongest antiviral activity and contained thirteen phlorotannins, which were predicted by dereplication. Ten compounds were directly isolated from E. cava extract and then identified. Moreover, the dereplication method allowed for the discovery of two new phlorotannins. The structures of these two isolated compounds were elucidated using NMR techniques and HPLC-qTOFMS fragmentation analysis. In addition, molecular modelling was applied to determine the absolute configurations of the two new compounds. The antiviral activities of seven major phlorotannins in active fraction were evaluated against two influenza A viral strains (H1N1 and H9N2). Six of the compounds showed moderate to strong effects on both of the viruses and phlorofucofuroeckol A (12), which showed an $\mathrm{EC}_{50}$ value of $13.48 \pm 1.93 \mu \mathrm{M}$, is a potential active antiviral component of E. cava.
\end{abstract}

Keywords: Ecklonia cava; bioactivity-guided isolation; dereplication; relative mass defect; HPLC-qTOFMS; antiviral; phlorotannins

\section{Introduction}

Ecklonia cava, which is edible seaweed belonging to the Laminariaceae family, is found in Asian countries, such as Japan and Korea. E. cava is a nutrient-dense food and it contains many types of organic compounds, including fucoidan and phlorotannins [1], which have various biological activities, such as antioxidant [2,3], anti-allergic [4], anti-plasmin inhibitory [5], anticancer [6], 
antihypertensive [7], and elastase and hyaluronidase inhibitory effects [8], as well as strong antiviral activity against porcine epidemic diarrhea virus (PEDV) (a coronavirus) [9].

Influenza, similar to coronaviruses, is also a contagious viral infection that causes acute respiratory illnesses and rapidly spreads through outbreaks $[10,11]$. The influenza virus belongs to the Orthomyxoviridae family, and there are three different types: A, B, and C. Among them, types A and $B$ are of great concern as human pathogens and result in seasonal or interpandemic epidemics as well as global pandemics, such as those that are caused by influenza A viruses [12,13]. Over the past 100 years, four pandemics have been reported: H1N1 Spanish influenza (1918), H2N2 Asian influenza (1957), H3N2 Hong Kong influenza (1968), and recently, 2009 H1N1 (H1N1pdm09), which are all caused by influenza A viruses $[12,14]$. In each pandemic, the number of novel virus strains arose and spread through human communities, leading to the substantial morbidity and mortality related to bacterial pneumonia $[11,15]$. The influenza A viruses are single-stranded negative-sense RNA viruses that are subtyped on the basis of the composition of their two surface glycoproteins: hemagglutinin (HA) and neuraminidase (NA) [16]. The genome of influenza A viruses comprises 8 separated gene segments encoding 16 proteins and is surrounded by a liquid envelope $[17,18]$. Two glycoproteins, HA and NA, are found in the viral envelopes, and these are considered to be the basis of antigenicity. HA initiates the infection of influenza virus by binding to the $\alpha-2,6$-linked sialic acid and/or $\alpha-2,3$-linked sialic acid receptors on the surface of the host cell, followed by receptor-mediated endocytosis of the virion into the cell $[17,19]$. The NA protein serves as a sialidase, and it cleaves the link between the sialic acid and the HA protein to release the virus particles [11,19]. To date, the Food and Drug Administration (FDA) [20] have approved only three drugs: Tamiflu (oseltamivir phosphate), Relenza (zanamivir), and Rapivab (peramivir).

Dereplication is the term that is used to discover new natural materials through the rapid identification of compounds that are based on new analytical tools, such as MS and NMR spectroscopy, to avoid the re-isolation of known components. In particular, the rapid development of modern MS techniques has accelerated dereplication strategies using high-performance liquid chromatography—quadrupole time-of-flight mass (HPLC-qTOFMS) spectra with tandem database searching to identify the known compounds in the extract [21]. By increasing the use of high-resolution mass spectrometry (HRMS) for measuring exact masses, the concept of "mass defect" is also increasingly being used in natural products research [22]. The mass defect is calculated as the deviation between the exact mass and the nominal mass (integer-rounded mass) of a compound [22,23]. Several methods have been developed to simplify the use of mass defects, including Kendrick mass defects, mass defect filtering, and fractional mass, which have played an important role in identifying many previously unknown compounds. In addition, a relative mass defect (RMD), calculated as (mass defect/measured monoisotopic mass) $\times 10^{6}$ in ppm, was recently introduced [23,24]. The RMD remains constant for classes that share the same fractional hydrogen content, which is useful in classifying the compounds into groups with the same skeleton [23]. While fatty acids or hydrocarbons with high hydrogen contents show high RMDs (400 to $600 \mathrm{ppm}$ ), the values for polyphenolic metabolites are often less than $300 \mathrm{ppm}$ due to their high oxygen contents [23]. In addition to modern techniques, such as HPLC-qTOFMS, classical bio-guided isolation has played an important role in the primary bioactive screening and identification of potential natural products. Pre-fractionation has recently been applied in bioactivity-guided isolations as an important step in obtaining bioactive materials. This is because the activities of minor components can be masked or decreased by more abundant inactive compounds in the total extract [25]. The combination of bio-guided isolation and dereplication enables the rapid and effective identification of the potential bioactive compounds [26].

The aim of the present study was to develop a new antiviral agent from E. cava. Specifically, we want to develop dereplication methods, including classification that is based on RMD and HPLC-qTOFMS, to accurately and rapidly identify bioactive phlorotannin-type compounds in E. cava, as well as to easily target new compounds. 


\section{Results and Discussion}

\subsection{Bioactivity-Guided Isolation and Dereplication of the Active Antiviral Fraction}

2.1.1. Bioactivity-Guided Fractionation Based on Antiviral Activity Against Human Influenza H1N1 $\mathrm{A} / \mathrm{PR} / 8 / 34$ Virus

The $80 \% \mathrm{MeOH}$ extract of E. cava, which showed antiviral activity at $10 \mu \mathrm{g} / \mathrm{mL}$ in a cytopathic effect (CPE) assay when compared to ribavirin $(10 \mu \mathrm{M})$ as a positive control (Figure $1 \mathrm{~A})$, was divided into five fractions on a Diaion HP-20 column, with a gradient of $\mathrm{MeOH}$ and $\mathrm{H}_{2} \mathrm{O}(0 / 100 \rightarrow 100 / 0$, $v / v$ ), and finally acetone. The antiviral activities of the five fractions indicated that the sub-fraction eluted with $70 \% \mathrm{MeOH}$ (EC70) had the strongest antiviral activity against H1N1-infected cells at three different concentrations $(5,10$, and $20 \mu \mathrm{g} / \mathrm{mL}$, Figure 1B). Thus, the EC70 fraction was chosen for further bio-guided isolation and dereplication using an HPLC-qTOFMS to identify the predicted bioactive compounds (Figure 2). Potential components against H1N1 and H9N2 viruses were further tested against viral protein synthesis of the H1N1 A/PR/8/34 virus (Figure 3).

A

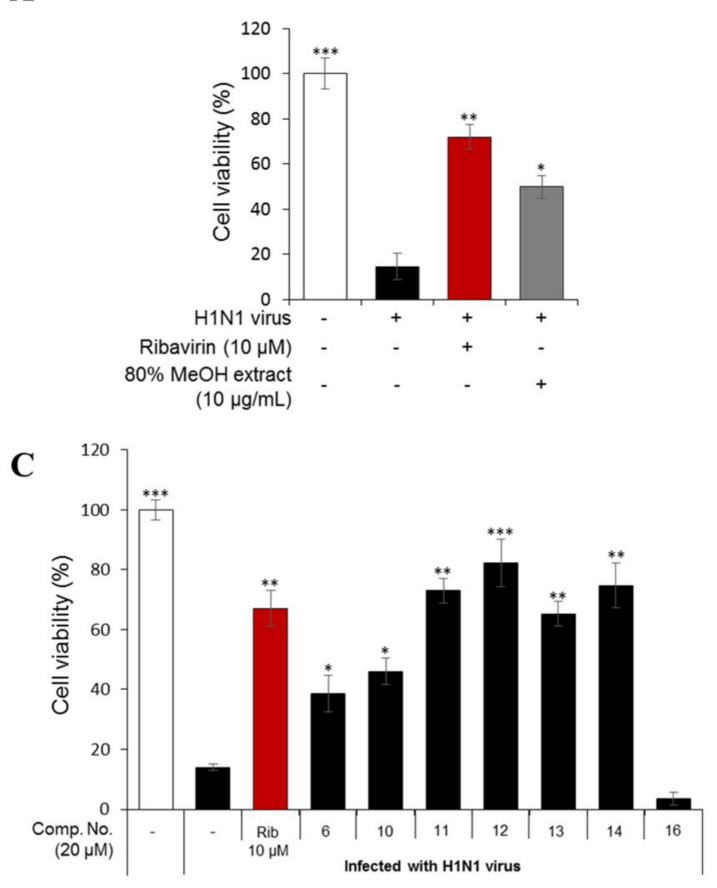

B

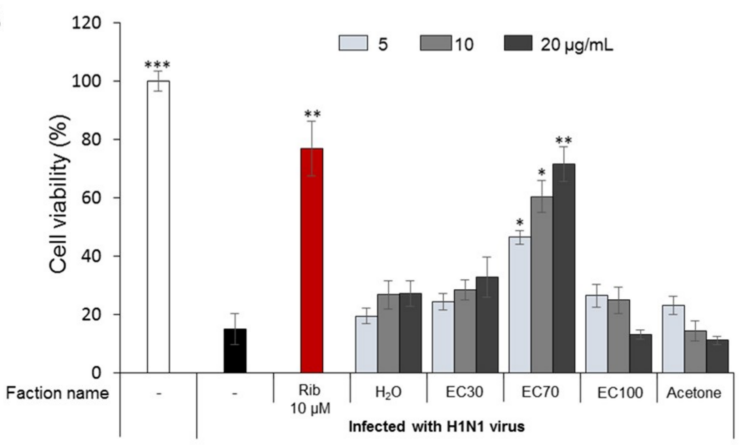

D

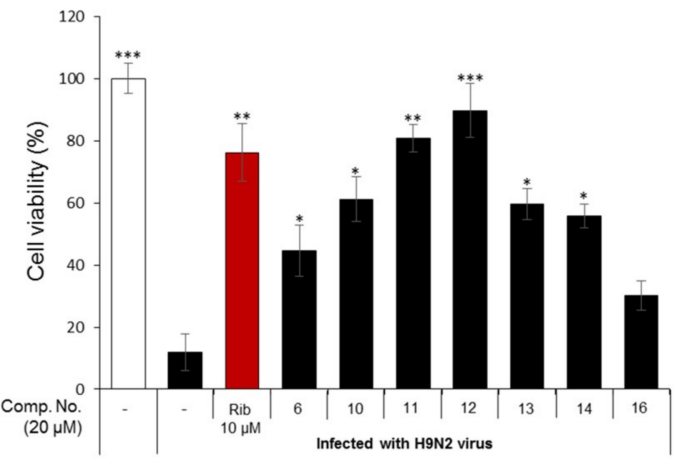

Figure 1. Cytopathic effect (CPE) inhibition assay to determine the antiviral activities of the $80 \%$ methanol extract of E. cava at $10 \mu \mathrm{g} / \mathrm{mL}$ (A) and five fractions (separated from the total extract with an open HP-20 column) (B) against the H1N1 A/PR/8/34 virus. In addition, the antiviral effects of compounds $\mathbf{6}, \mathbf{1 0}, \mathbf{1 1}, \mathbf{1 2}, \mathbf{1 3}, \mathbf{1 4}$, and 16 against H1N1 A/PR/8/34 virus (C) and H9N2 A/chicken/Korea/01210/2001 virus (D). Madin-Darby canine kidney (MDCK) cells were infected with the influenza viruses for $2 \mathrm{~h}$ and then treated with the test compounds or ribavirin $(10 \mu \mathrm{M})$ as a positive control. The percentage of cell survival was evaluated after three days of incubation using a CPE inhibition assay. Data are expressed as the mean $\pm \operatorname{SD}(n=3),{ }^{*} p<0.05,{ }^{* *} p<0.01$, and *** $p<0.001$ as compared to the virus control group.

2.1.2. Dereplication and Isolation of the Phlorotannins from the EC70 Fraction Using HPLC-qTOFMS and RMD

The dereplication of the secondary metabolites from E. cava was accomplished by HPLC-qTOFMS analysis of the active fraction (EC70). The HPLC-qTOFMS data were used for database construction based on the chromatographic retention times, full-scan (high-resolution) mass spectra, and MS/MS 
spectra in negative electrospray ionization (ESI) mode. The secondary metabolites in the EC70 fraction were identified by comparison with compounds that were previously reported in the Ecklonia genus (12 species listed in Table S1, Supporting Information) in online (Scifinder) and in-house databases that are based on exact mass and RMD using MassHunter quantitative B4.00 software. The identified compounds are shown as the base peaks of the MS and MS/MS chromatograms in Figure 4B-E. The $\mathrm{MS}^{1}$ and $\mathrm{MS}^{2}$ data of all the peaks that were detected in the spectra are listed in Table 1. The RMD value of each peak was used to determine its chemical skeleton. The structures of the components, which were identified by the comparison of the MS/MS fragmentations of the peaks in Table 1 to those in the in-house library, are shown in Figure 2.

The components on the EC70 fraction could be classified as phlorotannins, fatty acids, and others compounds with different ranges of RMD values. The RMD values of the detected phlorotannins were smaller than those of the other compounds, which are only approximately 10 to 200 ppm due to the nature of the structure of phlorotannins (Figure S15, Supporting Information). Positive absolute mass defects are usually observed in compounds that contain a large number of hydrogen atoms (mass defect $+7.83 \mathrm{mDa}$ ), whereas the lower values are observed in compounds with large numbers of oxygen (mass defect $-5.09 \mathrm{mDa}$ ) and nitrogen atoms (mass defect $+3.07 \mathrm{mDa}$ ) [23]. Fatty acids contain many hydrogens and they have large RMD values (as suggested by compounds 21, 22, 24, and 26-29, Table 1 and Figure 2), but oxygen is a major elementary building block of phlorotannins, which reduces the RMD values of this group, particularly in this study, to less than 200 ppm (as demonstrated by compounds 6-18, Table 1). These features are very helpful for further studying the genus Ecklonia, which contains phlorotannins as major components. As the first step of screening by HPLC-qTOFMS, the calculation of RMD values for all detected peaks facilitates the identification of phlorotannins and allows researchers to dereplicate the reported compounds, especially in this genus. The RMD values in the list of unidentified peaks in Table 1 are also useful for estimating the types of structures that are associated with detected peaks.

Furthermore, polyphenols have lower hydrogen contents and higher oxygen contents when compared to other types of compounds, resulting in lowered RMD values, which is consistent with what is seen in phlorotannins. Thus, in further studies, classification that is based on the RMD value is suitable for other types of polyphenolic compounds and it can be broadly applied in the screening of natural resources. In particular, for most species of brown algae, phlorotannin-type compounds can easily be classified because they are the main components of this species.

Phlorotannins, which are composed of phloroglucinol (1,3,5-trihydroxybenzene) units [27,28], are well-known as major components of the genus Ecklonia [9]. Overall, phlorotannins are divided into four classes that are based on the type of linkage that connects the phloroglucinol units, including ether-bound phlorotannins (fuhalols and phlorethols), phenyl-bound phlorotannins (fucols), ether and phenyl-bound phlorotannins (fucophlorethols), and dibenzo-dioxin-bound fucophlorethols (eckols and carmalols) $[27,28]$. Monomers in each class can be linked at various positions; thus, it is possible to have many structural isomers with the same molecular weight $[27,28]$. The fragmentation patterns that were observed for these peaks are therefore key to structural identification, as they indicate different losses of phloroglucinol monomers and hydroxyl groups [27]. In most previous studies, it has been necessary to isolate the compounds and use a combination of MS and NMR spectroscopy to elucidate the exact structures of phlorotannins [27]. Recently, an attempt was made to classify the types of phlorotannins in Sargassum fursiforme without isolation using ultrahigh-performance liquid chromatography triple quadrupole tandem mass spectrometry (UHPLC-QqQ-MS) for the first time. In this study, we proposed an efficient method to dereplicate the various phlorotannins derivatives, which are major constituents in seaweeds, based on preliminary HPLC-qTOFMS accompanied by RMD analysis. Moreover, the hypothesis of dereplication was further validated by the isolation and structural elucidation of phlorotannins using NMR and HPLC-qTOFMS. The MS/MS data of the peaks that were detected in the EC70 fraction and the anticipated components are listed in Table 1. As shown in Figure $4 \mathrm{C}$ and Table 1, forty-one peaks were observed in the HPLC-qTOFMS spectroscopic data of the 
active fraction, and compounds 6-18 (Table 1) were identified as phlorotannins based on a comparison of their RMD values, molecular weights, and MS/MS fragments to the literature data. According to their MS/MS data, thirteen compounds were identified as eckol-type phlorotannins, which contain at least one 1,4-dibenzodioxin fragment in their structures and have been mostly found in Ecklonia and some other genus of seaweeds $[27,28]$. The fragment peaks that were observed in the MS/MS patterns of these compounds revealed the losses of phloroglucinol (126 amu), pentahydroxyl dibenzodioxin (263 amu) and eckol (371 amu) based on the dominant product ions at $m / z 229 \mathrm{amu}$ [371 (eckol) -126 (phloroglucinol) -16 (oxygen atom) amu] and 261 amu [263 (pentahydroxyl dibenzodioxin) $-2 \mathrm{H}$ ]. For example, bieckol (compound 15, $\mathrm{m} / \mathrm{z}$ 741.0737, Table 1) showed product ions at $\mathrm{m} / \mathrm{z} 615,479$, 371 , and 260 from losses of one phloroglucinol (-126 amu), two phloroglucinols and a water $(-249$ $-18 \mathrm{amu}$ ), eckol ( $-371 \mathrm{amu})$, and eckol with a phloroglucinol being followed by the attachment of an oxygen atom $(-371-126+16 \mathrm{amu})$.
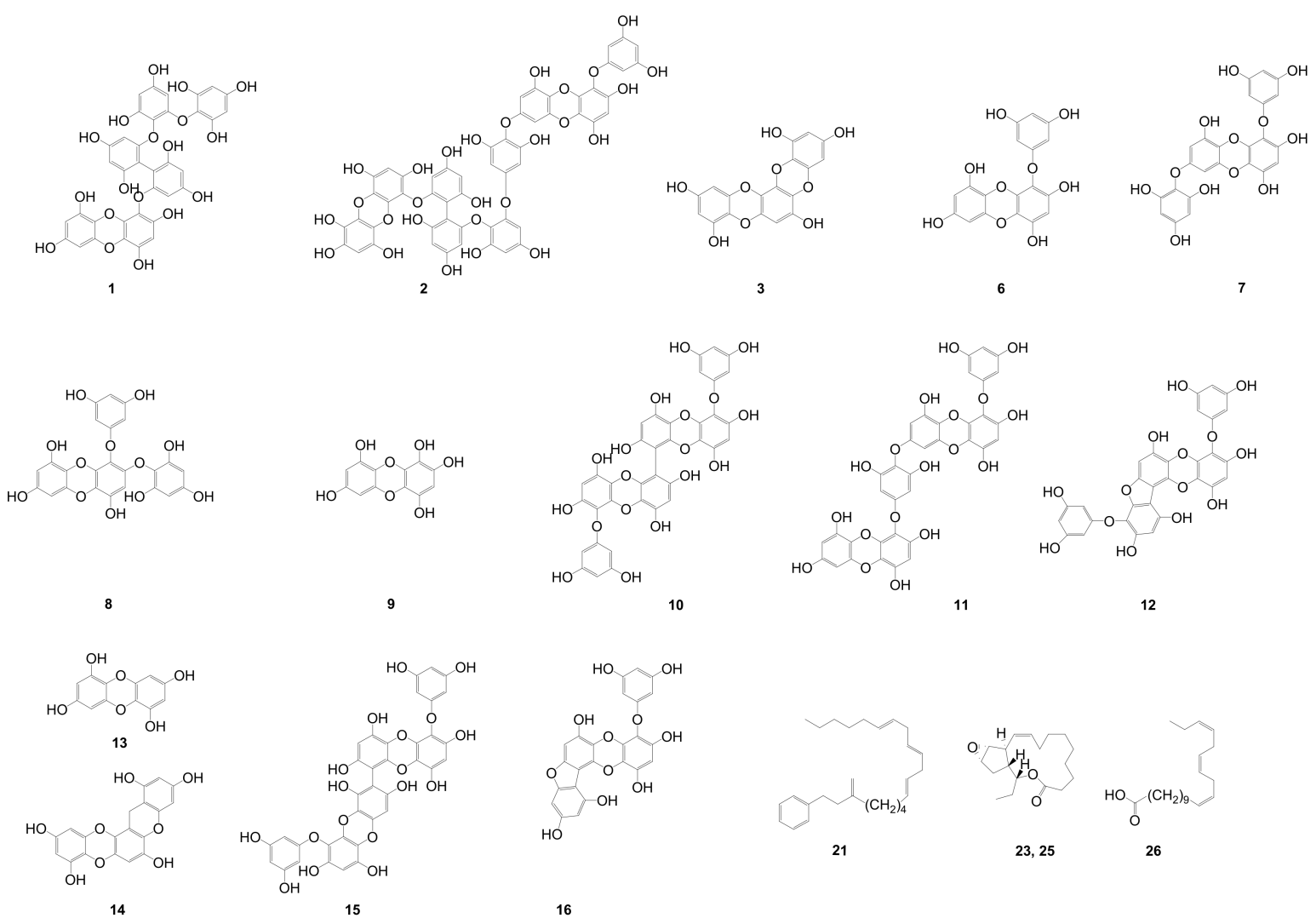

15
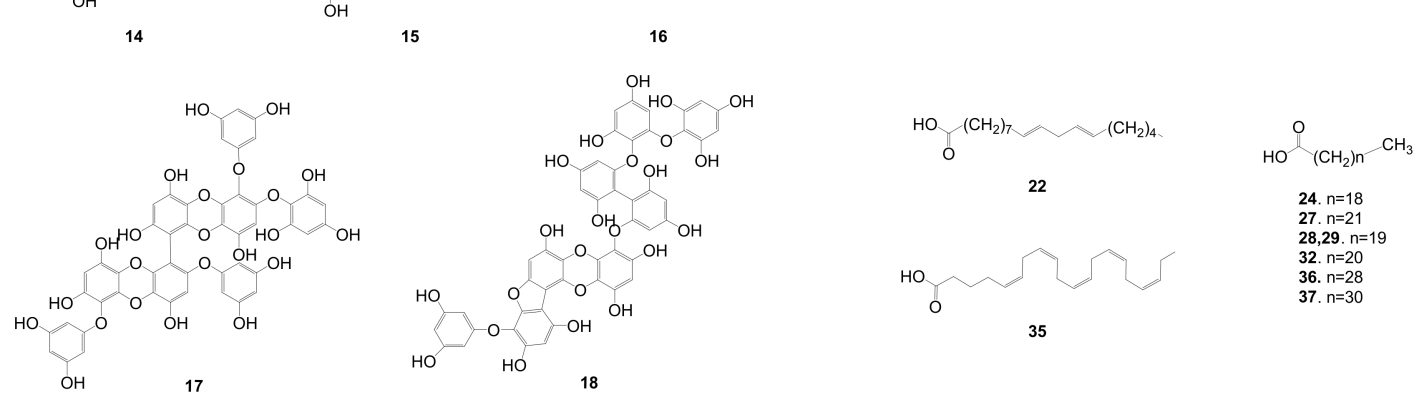

Figure 2. Identified phlorotannins and other compounds predicted by dereplication with high-resolution mass spectrometry and relative mass defect (RMD) values based on in-house and online databases. MassHunter software was used in this prediction.

According to dereplication results, ten known phlorotannins $(6,7,10-16$, and 18) were directly isolated from the EC70 fraction to validate the accuracy of the identification. These ten compounds were measured HPLC-qTOFMS in negative ion mode at a collision energy of $50 \mathrm{eV}$ to further confirm their 
retention times (Figure S16, Supporting Information). The fragmentation patterns of the isolated phlorotannins are presented in Figure S17 (Supporting Information). The results revealed that HPLC-qTOFMS was a powerful tool for identifying the structure of phlorotannins, especially in the cases of isomers, as it can provide sufficient data for the elucidation of the chemical structures. As an example, the MS/MS fragmentation pattern of compound $18(\mathrm{~m} / z$ 974.1038) is presented in detail. As identified in Table 1, compound 18 was established as compound 974-A due to its low RMD value (107 ppm) and the characteristic fragments that were observed at $m / z 973,707,353$, and 229 [29]. After isolation, the exact structure of $\mathbf{1 8}$ was further confirmed by NMR spectroscopy in conjunction with MS/MS fragmentation (Figure S17, Supporting Information). The product ions of $\mathbf{1 8}$ are shown in Figure S17 (Supporting Information) and they are due to the losses of bifuhalol (-266 amu), three phlorotannins and one water $(-375-18 \mathrm{amu})$, and four phlorotannin units and one water $(-448$ $-18 \mathrm{amu}$ ). Similarly, although compounds 10, 11, and 15 showed the same molecular ions ([M $-\mathrm{H}]^{-}$ of 741.0647, 741.0723, and 741.0737, respectively) (Table 1), they could be distinguished by their NMR data and different fragment ions in their MS/MS patterns (Figure S17, Supporting Information). In particular, compound 10 showed fragments at $m / z$ 619.0680, 495.0568, and 250.0477 from the losses of phloroglucinol (126 amu) and two equivalents of phloroglucinol (250 amu). Compound 11 generated product ion peaks at $m / z 565.3355,437.0064,369.0253$, and 230.9843 from the losses of phloroglucinol and three waters (176 amu) and a dioxinodehydroeckol (369 amu). 15 showed product ions at $m / z$ $477.0398,369.0198,351.0087$, and 125.0224, due to the losses of two molecules of phloroglucinol and water $(264 \mathrm{amu})$ and three phloroglucinol units (372 amu).

2.1.3. Antiviral Activities of the Major Phlorotannins in the EC70 Active Fraction against H1N1 and H9N2

In this study, seven major phlorotannins that were isolated from the EC70 fraction using bioactivity-guided isolation were tested for their antiviral activities against two influenza A viral strains (H1N1 A/PR/8/34 and H9N2 virus strains) (Figure 1C,D). The results indicated that six compounds (6 and 10-14) had moderate to strong antiviral activities against both viral strains at a concentration of $20 \mu \mathrm{M}$. Compounds 11-14, which displayed potent antiviral effects, were further tested against viral protein synthesis of the $\mathrm{H} 1 \mathrm{~N} 1 \mathrm{~A} / \mathrm{PR} / 8 / 34$ virus and compared to ribavirin as a positive control. The results, as shown in Figure 3A and Table S2 (Supporting Information), suggested that compound $\mathbf{1 2}$ was the most active compound with an $\mathrm{EC}_{50}$ of $13.48 \pm 1.93 \mu \mathrm{M}$. Thus, the dose-dependent inhibitory effects of compound $\mathbf{1 2}$ on viral protein synthesis were evaluated at four different concentrations 5, 10, 20, and $40 \mu \mathrm{M}$ in Madin-Darby canine kidney (MDCK) cells. As shown in Figure 3B, it is clear that, at higher concentrations, $\mathbf{1 2}$ more effectively inhibited protein expression in viral-infected cells. Compound $\mathbf{1 2}$ decreased the expression of neuraminidase and hemagglutinin at $10 \mu \mathrm{M}$, and the strongest inhibition capacity was observed at $40 \mu \mathrm{M}$. The fluorescence images that are shown in Figure $3 \mathrm{C}$ also explain the inhibitory effect of compound $\mathbf{1 2}$ on neuraminidase protein expression in H1N1 infected MDCK cells. The results suggested that compound 12 showed strong antiviral activity through inhibiting the expression of surface glycoproteins, hemagglutinin, and neuraminidase. 
A
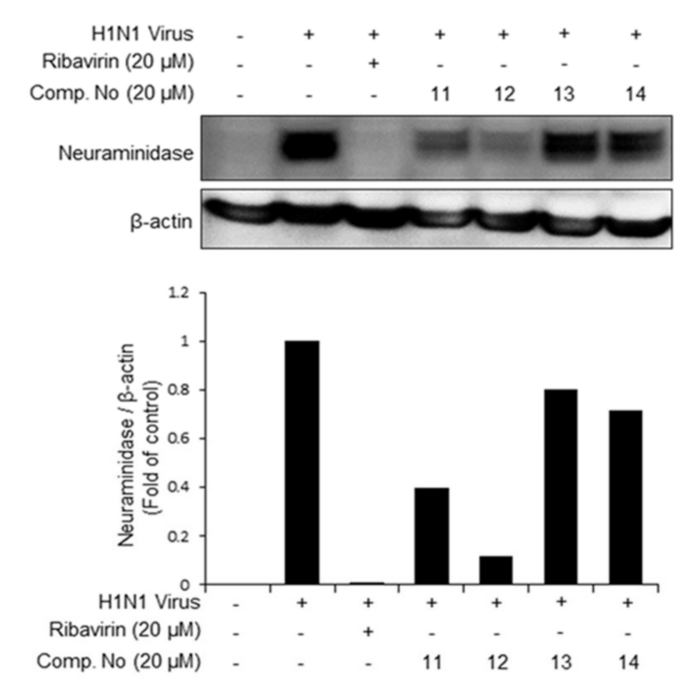

B

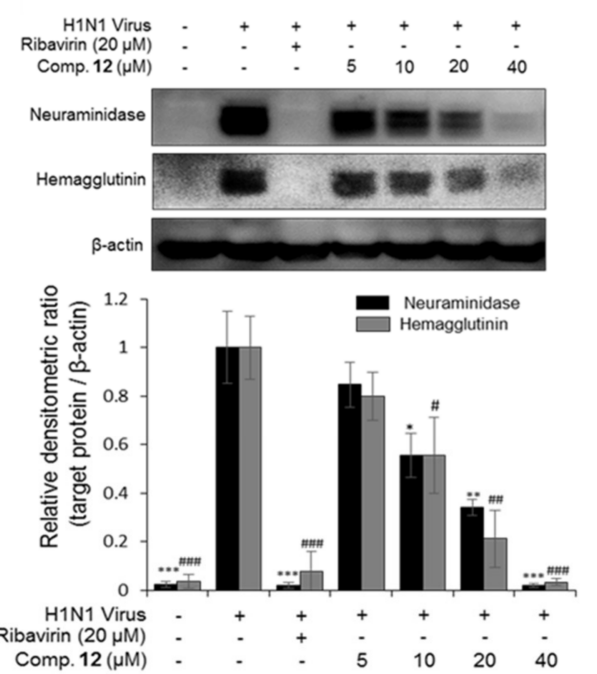

C

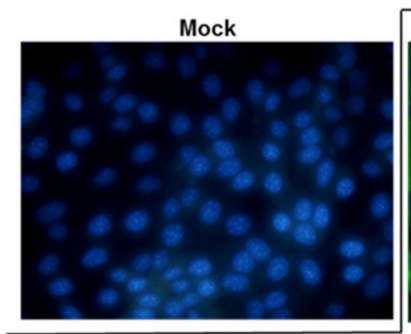

Comp. $12(10 \mu \mathrm{M})$

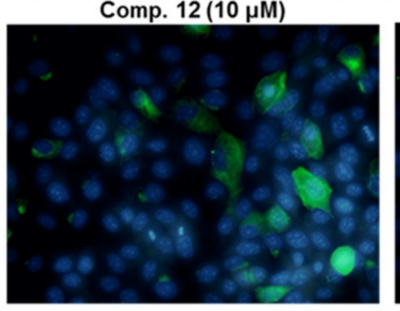

H1N1 virus infected in to MDCK cells

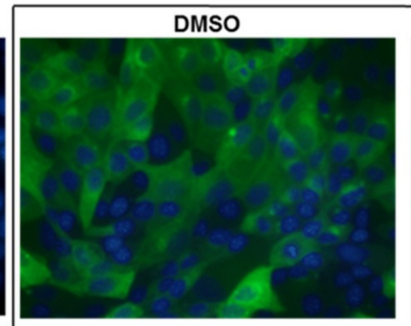

Comp. $12(20 \mu \mathrm{M})$

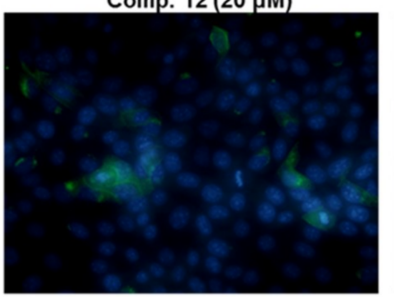

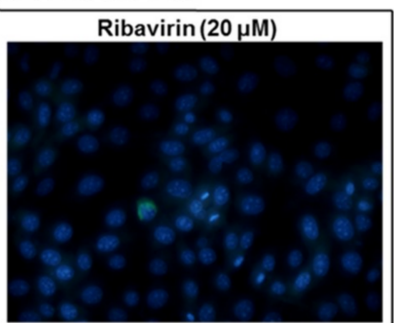

Comp. $12(40 \mu \mathrm{M})$

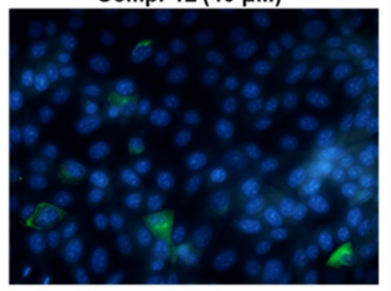

Figure 3. (A) The inhibitory effects of compounds 11, 12, 13, and 14 on viral protein synthesis. (B) The concentration-dependent inhibitory effect of compound $\mathbf{1 2}$ on viral protein synthesis. MDCK cells were infected with influenza H1N1 virus for $2 \mathrm{~h}$ and then treated with the test compounds or ribavirin (20 $\mu \mathrm{M})$ as a positive control for $24 \mathrm{~h}$. Western blotting was performed with $\beta$-actin as an internal control and specific antibodies (neuraminidase and hemagglutinin). The data are presented as the mean $\pm \mathrm{SD}$ $(n=2-3),{ }^{*} p<0.05,{ }^{* *} p<0.01,{ }^{* * *} p<0.001$ and ${ }^{\#} p<0.05,{ }^{\# \#} p<0.01$, \#\# $p<0.001$ when compared to the neuraminidase and hemagglutinin virus control groups, respectively. (C) Compound 12 decreased neuraminidase protein expression in viral-infected cell cytoplasm at various concentrations $(10,20$, and $40 \mu \mathrm{M})$. The fluorescence images were determined by immunocytochemistry using a fluorescence microscope.

\subsection{Identification of Two New Phlorotannins from the EC30 Fraction of E. cava using Dereplication and RMD Rules}

The results from the dereplication of the EC70 fraction suggested a quick method to identify phlorotannins. Hence, we attempted to isolate the new phlorotannins from the other fractions of E. cava based on their MS/MS fragmentation patterns and RMD values. The HPLC-qTOFMS data from fraction EC30 of E. cava was exported and the RMD values of the detected peaks were calculated. Compounds $1(\mathrm{~m} / \mathrm{z}$ 743.0881, Table 1$)$ and $2(\mathrm{~m} / \mathrm{z}$ 1113.1146, Table 1$)$ showed RMD values that were between 0 and 200 ppm, and their fragments, which were not presented in the in-house database or 
online database of the Ecklonia genus, suggested that these compounds might be new phlorotannins (Figure 4A). Thus, the two compounds were isolated to confirm their chemical structures through NMR spectroscopy along with molecular modelling and MS/MS fragmentation analysis.

Compound 1 was obtained as a brown powder and its molecular formula was determined to be $\mathrm{C}_{36} \mathrm{H}_{24} \mathrm{O}_{18}$ from its deprotonated ion peak at $m / z 743.0895$ (calcd. for $[\mathrm{M}-\mathrm{H}]^{-}, 743.0890$, Figure S1, Supporting Information). The chemical shifts observed in the ${ }^{1} \mathrm{H}$ and ${ }^{13} \mathrm{C}$ NMR spectra (Figures S3, and 4, Supporting Information), proton resonances in the downfield region of the aromatic chemical shift range, suggested a polyphenolic structure. In the ${ }^{1} \mathrm{H}$ NMR spectrum, eleven aromatic protons were observed, including one proton singlet at $\delta_{\mathrm{H}} 6.12(\mathrm{H}-3)$, one $2 \mathrm{H}$ overlapped singlet at $\delta_{\mathrm{H}} 5.86$ $\left(\mathrm{H}-3^{\prime \prime \prime \prime}, 5^{\prime \prime \prime \prime}\right)$, and four sets of meta-coupled doublets $\left[\delta_{\mathrm{H}} 6.12\right.$ (overlap, $\left.\mathrm{H}-5^{\prime \prime}\right) / 5.70\left(\mathrm{~d}, 1.5, \mathrm{H}-3^{\prime \prime}\right)$, 6.09 (br s, H-6')/5.99 (d, 1.5, H-2') 5.97 (d, 2.7, H-8)/5.81 (d, 2.7, H-6), and 589 (d, 2.7, H-5'"')/5.54 $\left.\left(\mathrm{d}, 2.7, \mathrm{H}-3^{\prime \prime \prime}\right)\right]$. The ${ }^{13} \mathrm{C}$ NMR signals corresponded to thirteen unsubstituted $\left(\delta_{\mathrm{C}} 92.7-100.7 \mathrm{ppm}\right)$ and twenty-three oxygenated aromatic carbons $\left(\delta_{C} 122.1-158.1 \mathrm{ppm}\right)$, which were assigned based on their HSQC and HMBC correlations (Figures S5 and S6, respectively, Supporting Information). These data suggested that the compound contained six phloroglucinol units. The coupling constants of the proton signals and HMBC data further confirmed the pattern of the substituents on $\mathbf{1}$ (Figure S20A, Supporting Information). The signal at $\delta_{\mathrm{H}} 6.12(1 \mathrm{H}, \mathrm{s})$ and the meta-coupled doublets at $\delta_{\mathrm{H}} 5.89(\mathrm{~d}, 2.7)$ and $5.81(\mathrm{~d}, 2.7)$ were similar to those of eckol [30], and they were thus assigned to $\mathrm{H}-3$ and $\mathrm{H}-8 / \mathrm{H}-6$ of rings A and B, respectively. Similarly, the structure of $\mathbf{1}$ was presumed to include the C, D, E, and F rings of fucodiphloroethol $\mathrm{G}$ by comparison with the reported NMR data [31]. The two carbon signals at $\delta_{C} 100.7$ and $101.4 \mathrm{ppm}$ also indicated that the structure of $\mathbf{1}$ contained one $\mathrm{C}-\mathrm{C}$ bond similar to that of fucodiphloroethol G [31]. However, the asymmetric structure of the $\mathrm{C}$ ring revealed that fucodiphloroethol and eckol moieties of $\mathbf{1}$ were linked through the $\mathrm{C}$ ring. The ROESY correlation of H-3 (A ring) with 5'-hydroxyl (C ring) (Figure S7, Supporting Information) suggested a phenyl linkage connecting the $\mathrm{C}$ and $\mathrm{A}$ rings. The long-range couplings between the proton of rings $\mathrm{A}$ and $\mathrm{C}$, as well as rings $B$ and $E$, were explained by their positions derived from three-dimensional structure optimization using molecular modelling (Figure S20B, Supporting Information). A comprehensive explanation of the structure was obtained from the MS/MS data. As shown in Figure S17 (Supporting Information), the fragment ion corresponding to $\mathrm{C}_{24} \mathrm{H}_{15} \mathrm{O}_{11}(\mathrm{~m} / \mathrm{z} 479.0608$, calcd 479.0614, $\Delta-0.6$ $\mathrm{mmu}$ ) was the main fragment of $\mathbf{1}$, and the other detected fragments were explained by the losses of phloroglucinol units $(-126 \mathrm{amu})$ or pentahydroxyl dibenzodioxin $(263 \mathrm{amu})$. In particular, the fragments of 1 at $m / z 583.0716,479.0608,353.0284$, and 265.0342 amu were from the losses of one phloroglucinol and two water molecules $(-126-34 \mathrm{amu})$, two phloroglucinol units and one oxygen atom $(-248-16 \mathrm{amu})$, three phloroglucinol and one water $(-372-18 \mathrm{amu})$, and pentahydroxyl dibenzodioxin and two protons ( $-263-2 \mathrm{amu})$. Therefore, the chemical structure of $\mathbf{1}$ was determined to be dibenzodioxin-fucodiphloroethol (DFD). 
A $M S / M S(E C 30)$

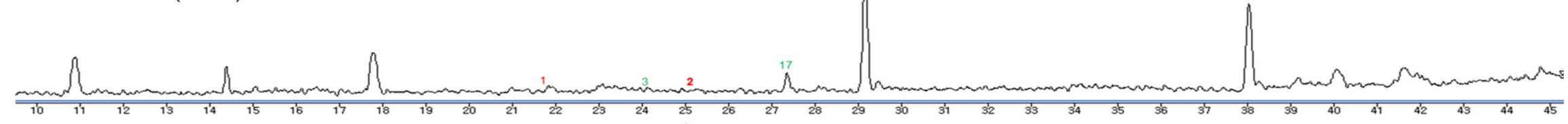

B

MS/MS (EC70)

Full scan MS (EC70)
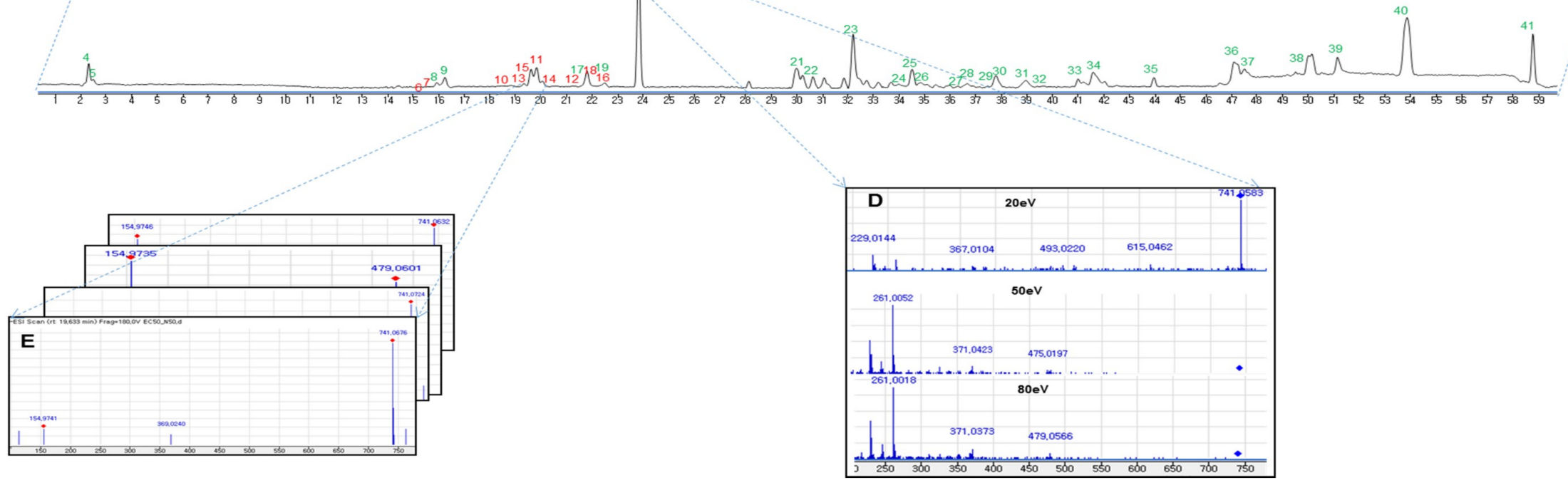

Figure 4. Base peak chromatograms of the high-performance liquid chromatography-quadrupole time-of-flight mass (HPLC-qTOFMS) spectra of the EC30 (A) and EC70 (B-E) fractions of E. cava in negative ionization mode at a collision energy of $50 \mathrm{eV}$. The chromatograms were generated using MassHunter software. Full scan, high-resolution mass spectrometry screening (C,E); MS/MS identification using an in-house library of the Ecklonia genus with different collision energies from 20 to $80 \mathrm{eV}$ (B,D). 
Table 1. MS/MS fragmentation of the peaks detected in the total ion chromatograms of the EC30 and EC70 fractions of E. cava in negative ionization mode.

\begin{tabular}{|c|c|c|c|c|c|c|c|c|c|}
\hline No & Compound Name & RT (min) & MS $^{1}$ & MS $^{2}$ & {$[\mathbf{M}-\mathbf{H}]^{-}$} & $\begin{array}{l}\text { Chemical } \\
\text { Formula }\end{array}$ & Calcd. Mass & Dif. & RMD \\
\hline 1 & Compound 1 & 21.793 & $\begin{array}{c}195,247,389,479,583 \\
743\end{array}$ & $\begin{array}{c}139,231,285,353,447, \\
493,643,743\end{array}$ & 743.0881 & $\mathrm{C}_{36} \mathrm{H}_{23} \mathrm{O}_{18}$ & 743.0884 & -1.73 & 119 \\
\hline 2 & Compound 2 & 25.279 & $\begin{array}{c}195,359,479,556,663 \\
982,1113\end{array}$ & $\begin{array}{c}231,353,461,705,925, \\
1104,1113\end{array}$ & 1113.1146 & $\mathrm{C}_{54} \mathrm{H}_{33} \mathrm{O}_{27}$ & 1113.1209 & -7.94 & 103 \\
\hline 3 & $\begin{array}{l}\text { Benzo[1,2-b:3,4-b']bis[1,4] } \\
\text { benzodioxin-1,3,6,9,11-pentol }\end{array}$ & 24.015 & $195,211,246,292,369$ & $\begin{array}{c}193,230,267,285,310, \\
369\end{array}$ & 369.0224 & $\mathrm{C}_{18} \mathrm{H}_{9} \mathrm{O}_{9}$ & 369.0247 & -4.80 & 61 \\
\hline 4 & Unknown & 2.268 & 162,197 & 163,821 & 162.8392 & - & & & 5154 \\
\hline 5 & Unknown & 2.631 & $122,139,168,195$ & 111, 139, 171 & 195.9504 & - & & & 4850 \\
\hline 7 & 7-Phloroeckol & 15.845 & 154,495 & $\begin{array}{c}263,297,387,488,495, \\
616\end{array}$ & 495.0511 & $\mathrm{C}_{24} \mathrm{H}_{15} \mathrm{O}_{12}$ & 495.0564 & -7.28 & 103 \\
\hline 8 & 2-Phloroeckol & 16.003 & $154,263,495$ & $201,229,283,346,495$ & 495.0528 & $\mathrm{C}_{24} \mathrm{H}_{15} \mathrm{O}_{12}$ & 495.0564 & -6.00 & 107 \\
\hline 9 & $\begin{array}{l}\text { Dibenzo[b,e][1,4]dioxin-1, } \\
\text { 2,4,7,9-pentol }\end{array}$ & 16.209 & $137,155,263$ & $207,218,263$ & 263.0157 & $\mathrm{C}_{12} \mathrm{H}_{7} \mathrm{O}_{7}$ & 263.0192 & -5.92 & 60 \\
\hline 10 & 6,6'-Bieckol & 18.854 & 154,741 & $\begin{array}{c}229,261,371,479,585 \\
666,741\end{array}$ & 741.0647 & $\mathrm{C}_{36} \mathrm{H}_{21} \mathrm{O}_{18}$ & 741.0728 & -9.00 & 87 \\
\hline 13 & $\begin{array}{c}\text { Dibenzo[1,4]dioxine-2,4, } \\
\text { 7,9-tetraol }\end{array}$ & 19.274 & $123,155,247$ & $141,195,247,385,479$ & 247.0243 & $\mathrm{C}_{12} \mathrm{H}_{7} \mathrm{O}_{6}$ & 247.0243 & 0.00 & 98 \\
\hline 15 & $6,8^{\prime}$-Bieckol & 19.569 & 741 & $260,371,479,615,741$ & 741.0737 & $\mathrm{C}_{36} \mathrm{H}_{21} \mathrm{O}_{18}$ & 741.0728 & 3.00 & 99 \\
\hline 14 & Dioxinodehydroeckol & 20.370 & $123,196,325,369$ & $\begin{array}{c}123,161,173,199,261, \\
369\end{array}$ & 369.0269 & $\mathrm{C}_{18} \mathrm{H}_{9} \mathrm{O}_{9}$ & 369.0247 & 4.69 & 73 \\
\hline 12 & Phlorofucofuroeckol A & 21.796 & 155,601 & $245,385,447,493,601$ & 601.0640 & $\mathrm{C}_{30} \mathrm{H}_{17} \mathrm{O}_{14}$ & 601.0618 & 4.69 & 106 \\
\hline 17 & $\begin{array}{l}\text { 2,7"'-phloroglucinol } \\
\text { 6,6'-bieckol (PHB) }\end{array}$ & 22.018 & 155,973 & $\begin{array}{c}229,353,427,493,707, \\
806,973\end{array}$ & 973.1153 & $\mathrm{C}_{48} \mathrm{H}_{29} \mathrm{O}_{23}$ & 973.1100 & 7.28 & 118 \\
\hline 18 & 974-A & 22.050 & $113,601,973$ & $\begin{array}{c}229,353,393,605,707 \\
805,941\end{array}$ & 973.1038 & $\mathrm{C}_{48} \mathrm{H}_{29} \mathrm{O}_{23}$ & 973.1100 & -7.87 & 107 \\
\hline 19 & Unknown & 22.44 & $155,369,551$ & $223,304,551,583,710$ & 551.1816 & - & & & 329 \\
\hline 16 & Fucofuroeckol A & 22.897 & 155,477 & $2551,352,477,545$ & 477.0425 & $\mathrm{C}_{24} \mathrm{H}_{13} \mathrm{O}_{11}$ & 477.0457 & -5.66 & 89 \\
\hline 20 & Unknown & 23.799 & 242,310 & $201,271,348$ & 242.1758 & - & & & 726 \\
\hline 21 & $\begin{array}{l}\text { 6,9,12-Octadecatrienoic } \\
\text { acid, }(6 \mathrm{Z}, 9 \mathrm{Z}, 12 \mathrm{Z})\end{array}$ & 29.966 & 277,527 & $264,353,481$ & 277.2125 & $\mathrm{C}_{18} \mathrm{H}_{29} \mathrm{O}_{2}$ & 277.2168 & -6.56 & 767 \\
\hline
\end{tabular}


Table 1. Cont.

\begin{tabular}{|c|c|c|c|c|c|c|c|c|c|}
\hline No & Compound Name & $\mathrm{RT}$ (min) & MS $^{1}$ & MS $^{2}$ & {$[\mathbf{M}-\mathbf{H}]^{-}$} & $\begin{array}{l}\text { Chemical } \\
\text { Formula }\end{array}$ & Calcd. Mass & Dif. & RMD \\
\hline 22 & $\begin{array}{c}\text { 9,12-Octadecadienoic acid } \\
(9 \mathrm{Z}, 12 \mathrm{Z})\end{array}$ & 30.496 & 279 & $218,248,279,346,380$ & 279.2168 & $\mathrm{C}_{18} \mathrm{H}_{31} \mathrm{O}_{2}$ & 279.2324 & -12.49 & 776 \\
\hline 23 & Ecklonialactone B (R/S) & 32.281 & 265,291 & 201,291 & 291.2020 & $\mathrm{C}_{18} \mathrm{H}_{27} \mathrm{O}_{3}$ & 291.1960 & 7.75 & 694 \\
\hline 24 & Eicosanoic acid & 34.206 & 311 & $225,311,349$ & 311.2848 & $\mathrm{C}_{20} \mathrm{H}_{39} \mathrm{O}_{2}$ & 311.2950 & -10.10 & 915 \\
\hline 25 & Ecklonialactone B (S/R) & 34.499 & $291,555,623$ & $251,291,411,651$ & 291.1938 & $\mathrm{C}_{18} \mathrm{H}_{27} \mathrm{O}_{3}$ & 291.1960 & -4.96 & 666 \\
\hline 26 & $\begin{array}{l}\text { 11,14,17-Eicosatrienoic } \\
\text { acid, (11Z,14Z,17Z)- }\end{array}$ & 34.771 & 305 & $\begin{array}{c}211,284,305,248,583 \\
804\end{array}$ & 305.2410 & $\mathrm{C}_{20} \mathrm{H}_{33} \mathrm{O}_{2}$ & 305.2481 & -8.43 & 790 \\
\hline 27 & Tricosanoic acid & 36.294 & 353 & $257,333,353,529$ & 353.3407 & $\mathrm{C}_{23} \mathrm{H}_{45} \mathrm{O}_{2}$ & 353.3420 & -3.61 & 964 \\
\hline 29 & Unknown & 37.806 & 293,325 & $281,325,386,449,674$ & 325.1812 & - & & & 557 \\
\hline 30 & Unknown & 37.869 & 239,293 & $207,239,243,383$ & 239.0709 & - & & & 297 \\
\hline 31 & Unknown & 38.947 & 321 & $248,321,399,572,815$ & 321.2178 & - & & & 678 \\
\hline 32 & Docosanoic acid & 39.599 & 339 & $226,339,433,660,809$ & 339.3292 & $\mathrm{C}_{22} \mathrm{H}_{43} \mathrm{O}_{2}$ & 339.3263 & 5.39 & 970 \\
\hline 33 & Unknown & 41.028 & 346 & $206,254,330,346,642$ & 346.1092 & - & & & 316 \\
\hline 34 & Unknown & 41.59 & 346,485 & $280,421,485$ & 485.2671 & - & & & 550 \\
\hline 35 & $\begin{array}{c}\text { 5,8,11,14,17-Eicosapentaenoic } \\
\text { acid, (5Z,8Z,11Z,14Z,17Z) }\end{array}$ & 43.93 & 301,369 & $205,269,301,440$ & 301.2099 & $\mathrm{C}_{20} \mathrm{H}_{29} \mathrm{O}_{2}$ & 301.2168 & -8.31 & 697 \\
\hline 36 & Triacontanoic acid & 47.116 & $346,451,535,691,775$ & $295,387,451,456$ & 451.4499 & $\mathrm{C}_{30} \mathrm{H}_{59} \mathrm{O}_{2}$ & 451.4515 & -4.00 & 997 \\
\hline 39 & Unknown & 51.118 & 149,223 & 149,448 & 149.0021 & - & & & 14 \\
\hline 40 & Unknown & 53.856 & $149,223,297$ & $149,221,350,630.7708$ & 149.0086 & - & & & 58 \\
\hline 41 & Unknown & 58.796 & 135 & $135.9698,287.5036$ & 135.9751 & - & & & 7171 \\
\hline
\end{tabular}


Compound 2 was obtained as a brown powder and the molecular formula of $\mathbf{2}$ was established to be $\mathrm{C}_{54} \mathrm{H}_{34} \mathrm{O}_{27}$ on the basis of its molecular ion in the negative mode (HPLC-qTOFMS, $m / z$ 1113.1215, calcd. for $[\mathrm{M}-\mathrm{H}]^{-}$, 1113.1215) (Figure S8, Supporting Information). The ${ }^{1} \mathrm{H}$ NMR spectrum of 2 (Figure S10, Supporting Information) showed a total of sixteen proton signals, including three proton singlets at $\delta_{\mathrm{H}} 6.21\left(1 \mathrm{H}, \mathrm{s}, \mathrm{H}-5^{\prime \prime \prime \prime \prime \prime \prime}\right), 6.14\left(1 \mathrm{H}, \mathrm{s}, \mathrm{H}-4^{\prime \prime \prime \prime \prime \prime \prime \prime}\right)$, and $5.92(1 \mathrm{H}, \mathrm{s}, \mathrm{H}-3)$; two sets of meta-coupled doublets at $\delta_{\mathrm{H}} 6.01(1 \mathrm{H}, \mathrm{d}, 2.2 \mathrm{~Hz}, \mathrm{H}-6), 5.88(1 \mathrm{H}, \mathrm{d}, 2.2 \mathrm{~Hz}, \mathrm{H}-8), 5.89(1 \mathrm{H}, \mathrm{d}, 2.4$ $\left.\mathrm{Hz}, \mathrm{H}-5^{\prime \prime \prime}\right)$, and $5.55\left(1 \mathrm{H}, \mathrm{d}, 2.4 \mathrm{~Hz}, \mathrm{H}-3^{\prime \prime \prime}\right)$; two sets of meta-coupled $2 \mathrm{H}$ signals at $\delta_{\mathrm{H}} 5.87(2 \mathrm{H}, \mathrm{s}$, $\left.\mathrm{H}-3^{\prime \prime}, 5^{\prime \prime}\right), 5.74\left(2 \mathrm{H}, \mathrm{d}, 1.8 \mathrm{~Hz}, \mathrm{H}-2^{\prime}, 6^{\prime}\right)$, and $5.81\left(1 \mathrm{H}, \mathrm{br} \mathrm{t}, \mathrm{H}-4^{\prime}\right)$; and, two sets of meta-coupled singlets at $\delta_{\mathrm{H}} 6.14\left(1 \mathrm{H}, \mathrm{br} \mathrm{s}, \mathrm{H}-5^{\prime \prime \prime \prime}\right), 5.71\left(1 \mathrm{H}, \mathrm{br} \mathrm{s}, \mathrm{H}-3^{\prime \prime \prime \prime}\right), 6.11\left(1 \mathrm{H}, \mathrm{br} \mathrm{s}, \mathrm{H}-5^{\prime \prime \prime \prime \prime}\right)$, and $6.00(1 \mathrm{H}$, br s, $\left.\mathrm{H}-3^{\prime \prime \prime \prime \prime \prime}\right)$. The ${ }^{13} \mathrm{C}$ NMR spectrum of 2 (Figure S11, Supporting Information) showed 54 signals in the chemical shift range of aromatic carbons. The thirteen protonated carbon signals from $\delta_{\mathrm{C}}$ 92.7 to $98.7 \mathrm{ppm}$, along with thirty-six oxygenated aromatic carbon signals that were located in the range of 121.4-163.5 ppm, suggested the presence of nine aromatic rings in the structure of 2 . All of the carbon signals in ${ }^{13} \mathrm{C}$ NMR spectrum of 2 were assigned based on their HSQC and HMBC correlations (Table S3 and Figures S12 and S13, Supporting Information). When compared with the reported phlorotannins, the chemical shifts of the atoms in rings A, B, C, and D of 2 were similar to those belonging to 7-phloroeckol [32]. Similarly, the chemical shifts of the atoms in rings D, E, F, and $G$ were assigned based on the structure of fucodiphloroethol $G$ [31]. The $C-C$ bond between rings $F$ and $G$ of 2 was confirmed from the chemical shifts at $\delta_{C} 100.7$ and 101.5 ppm. In addition, the remaining two aromatic rings of 2 were suggested to be rings $\mathrm{H}$ and I based on the MS/MS fragmentation analysis of 2 . The fragment at $265 \mathrm{amu}$ was suggested by the vicinal trihydroxylated structure of compound 2 (Figure S17, Supporting Information), which was characteristic of a bifuhalol unit that contained an extra hydroxyl group on the terminal phlorotannin unit [27]. The connectivity between all of the fragments was further determined by the ROESY spectrum (Figure S14, Supporting Information). The correlations of the signals corresponding to $\mathrm{H}-2^{\prime} / 6^{\prime}$ in ring A with $\mathrm{H}-3$ (B ring) and H-6 (C ring) and between H-6 (C ring) with H-3 (D ring) confirmed the connectivity of these rings, as shown in Figure S20 (Supporting Information). The 7-phloroeckol moiety was connected to the $1^{\prime \prime \prime}$ position of the ring E based on the ROESY correlation between the H-3" (D ring) and $\mathrm{H}-6^{\prime \prime \prime}$ (E ring). Similar to compound 1, the long-range correlations of the protons on rings $A$ and $D$, as well as on rings B and G of $\mathbf{2}$, were further supported by the optimized three-dimensional structure obtained using molecular modelling (Figure S20B, Supporting Information). The fragment information from HRMS/MS data of 2, as described in Figure S17 (Supporting Information), also supported the chemical structure of compound 2. The fragments that were observed in Figure S17 (Supporting Information) at $m / z$ 989.0983, 879.0299, 556.0534, and $265.0334 \mathrm{amu}$ were explained by the losses of one phloroglucinol unit $(-126 \mathrm{amu})$; two phloroglucinol units and the addition of one water $(-252$ and $+18 \mathrm{amu})$; one eckol, one bifuhalol, the addition of one acetic acid, and one water $(-372-263+60+18$ $\mathrm{amu}$ ); and, a bifuhalol fragment at $265.0334 \mathrm{amu}$. Finally, the exact structure of $\mathbf{2}$ was elucidated as dibenzodioxin-fucodiphloroeckol (DFE).

\subsection{Discussion of the Potential Applications of the Developed Dereplication Strategy and Phlorotannins}

In this paper, the developed dereplication strategy using RMD values is based on the general dereplication strategy that determines the similarities between the MS/MS fragmentation patterns of standard compounds and those of the unknown compounds. However, unlike the general dereplication method, RMD can be used to group compounds of the same type to show the overall phytochemical trends by the types of secondary metabolites. The extracts of $E$. cava or phlorotannins (dieckol, phloroglucinol, eckol, phlorofucofuroeckol, and 7-phloroeckol, etc.) have been reported to have antiviral activities, such as PEDV [9], viral hemorrhagic septicemia virus (VHSV) [33], human papilloma virus (HPV) [34], and murine norovirus (MNV) [35]. However, in this study, a method of producing a bioactive fraction was developed, and this fraction could be used to obtain antiviral materials from a total extract. Additionally, seven lead compounds were identified and purified from 
the bioactive fraction. Therefore, the fraction of the E. cava extract and the isolated phlorotannins have been shown to be potentially industrially applicable in the prevention or treatment of influenza A viruses.

\section{Conclusions}

The present study discussed using MS/MS fragmentation analysis coupled with RMD filtering as a dereplication method to identify phlorotannins, which are bioactive substances in the Ecknolia genus, especially in Ecknolia cava. To the best of our knowledge, this is the first attempt to apply and post-evaluate the accuracy of the RMD values in conjunction with MS/MS analysis for the identification of phlorotannins. The results of the dereplication study provide a quick initial screening for the phlorotannin motif, as these compounds show RMD values of less than $200 \mathrm{ppm}$, typically with fragments from losses of phloroglucinol units. In addition, different ranges of RMD values suggest the presence of different types of structures that are present in the compound. MS/MS was not only useful for dereplication but it also provided strong evidence to confirm the structures of phlorotannins by their fragments. Based on this dereplication method, two new compounds were identified and further elucidated by spectroscopy. In addition, this study was conducted to identify the antiviral lead compounds from E. cava using bio-guided isolation. Our results suggested that phlorofucofuroeckol A (12) from E. cava plays a key role in the antiviral activities of this seaweed against H1N1 and H9N2 virus. The strong inhibitory effects of this compound against neuraminidase and hemagglutinin suggested that it could be a potential agent for the further development of antiviral drugs.

\section{Materials and Methods}

\subsection{General Experimental Procedures}

Optical rotations were determined on a JASCO P-2000 polarimeter (JASCO International Co. Ltd., Tokyo, Japan). The IR spectra were recorded on a Nicolet 6700 FT-IR spectrometer (Thermo Electron Corp., Waltham, MA, USA). NMR data were measured in DMSO- $d_{6}$ and recorded on 300, 800, and $850 \mathrm{MHz}$ spectrometers at the College of Pharmacy, Seoul National University, Korea. ESI-MS data were recorded on an Agilent 1100 series LC/MSD TRAP (Agilent Technologies, Waldbronn, Germany). The active fractions were analysed by TLC (thin-layer chromatography) on silica gel 60 F254 and RP-18 F254 plates from Merck (Darmstadt, Germany). Spraying with a vanillin reagent that contained $0.5 \mathrm{~g}$ of vanillin, $80 \mathrm{~mL}$ of sulfuric acid, and $20 \mathrm{~mL}$ of ethanol developed the plates, and the compounds on the TLC plates were detected at 254 and $365 \mathrm{~nm}$. Column chromatography separations were carried out using various resins, including Diaion HP-20 (Mitsubishi Chemical Co. Tokyo, Japan), Sephadex LH-20 (Sigma-Aldrich Corp, St. Louis, Missouri, USA), silica gel (Merck, 40-63 $\mu \mathrm{m}$ particle size), and $\mathrm{C}_{18}$-RP silica gel (Merck, 40-63 $\mu \mathrm{m}$ particle size). Preparative HPLC separations were performed by using a Gilson system with an Optima Pak $\mathrm{C}_{18}$ column $(10 \mathrm{~mm} \times 250 \mathrm{~mm}, 10 \mu \mathrm{m}$ in particle size, RS Tech, Seoul, Korea) and a UV detector at wavelengths of 205 and $254 \mathrm{~nm}$. All of the solvents that were used for extraction and isolation were of analytical grade. The most stable configuration of compounds 1 and 2 (Figure S20, Supporting Information) were calculated by CONFLEX 8 (Conflex Corp., Tokyo, Japan) using molecular mechanics force-field (MMFF94s) calculations with a search limit of $1.0 \mathrm{kcal} / \mathrm{mol}$.

\subsection{Plant Material}

E. cava was collected from Cheongsando Island, Republic of Korea in July 2016. Prof. T. O. Cho botanically identified the plant sample. A voucher specimen (TCMBRB0019/TC9484) was deposited at the Algae Systematics laboratory of Chosun University, College of Natural Sciences, Gwang-ju, Republic of Korea. 


\subsection{Extraction and Isolation}

Dried powder of E. cava $(100 \mathrm{~g})$ was extracted with $80 \% \mathrm{MeOH}(5 \mathrm{~L})$ at room temperature under ultra-sonication for two days. After filtration, the combined $\mathrm{MeOH}$ solution was concentrated under reduced pressure to yield dry extract $(20.4 \mathrm{~g})$. The crude extract was suspended in distilled water (2 L) and then fractionated using Diaion HP-20. Four litres of water was used to elute the salts and then two litres each of $30 \% \mathrm{MeOH}, 70 \% \mathrm{MeOH}, 100 \% \mathrm{MeOH}$, and $100 \%$ acetone were used as the elution systems to obtain five fractions. The fraction eluted with $30 \% \mathrm{MeOH}$ was chromatographed on a reversed-phase silica gel column with a gradient of $\mathrm{MeOH} / \mathrm{H}_{2} \mathrm{O}$ from $30 \%$ to $100 \%$ to yield five subfractions (F1-F5) (Scheme S1, Supporting Information). Sub-fraction F2 was subjected to a Sephadex LH-20 column that was eluted with $100 \% \mathrm{MeOH}$ to afford four fractions (F2.1-F2.4). Fraction F2.3 was further purified on a Sephadex column with $100 \% \mathrm{MeOH}$ to give three subfractions (F2.3.1-3). Subfraction F2.3.2 was further purified by semi-preparative HPLC [Optimapack $\mathrm{C}_{18}$ column $(10 \mathrm{~mm}$ $\times 250 \mathrm{~mm}, 10 \mu \mathrm{m}$ particle size, RS Tech, Seoul, Korea); mobile phase $\mathrm{MeCN}$ in $\mathrm{H}_{2} \mathrm{O}$ containing $0.1 \%$ $\mathrm{HCO}_{2} \mathrm{H}$ (0-40 min: 35 to $100 \% \mathrm{MeCN}$, 41-51 $\mathrm{min}: 100 \% \mathrm{MeCN}$ ); and, flow rate: $2 \mathrm{~mL} / \mathrm{min}$ ] to yield compounds $1(6.0 \mathrm{mg})$ and $2(5.0 \mathrm{mg})$. The $70 \% \mathrm{MeOH}$ fraction was separated by reversed-phase chromatography (40-63 $\mu \mathrm{m}$ particle size) with a stepwise elution gradient of $\mathrm{MeOH} / \mathrm{H}_{2} \mathrm{O}(2: 3-1: 0)$ to afford four subfractions (F70.1-F70.4). The fraction F70.1 was subjected to HPLC [Optimapack $\mathrm{C}_{18}$ column (10 mm $\times 250 \mathrm{~mm}, 10 \mu \mathrm{m}$ particle size, RS Tech, Seoul, Korea); mobile phase MeCN in $\mathrm{H}_{2} \mathrm{O}$ containing $0.1 \% \mathrm{HCO}_{2} \mathrm{H}(0-65 \mathrm{~min}: 20 \% \mathrm{MeCN}$, $65 \mathrm{~min}: 100 \% \mathrm{MeCN})$; flow rate: $2 \mathrm{~mL} / \mathrm{min}$ ] to afford compounds 11 (dieckol, $15.0 \mathrm{mg}$ ), 13 (dibenzo[1,4]dioxine-2,4,7,9-tetraol, $3.0 \mathrm{mg}$ ), 6 (eckol, $2.0 \mathrm{mg}$ ), and 10 (6,6'-bieckol, $2.0 \mathrm{mg})$. Subsequently, fraction F70.2 was separated by HPLC [Optimapack $\mathrm{C}_{18}$ column (10 mm $\times 250 \mathrm{~mm}, 10 \mu \mathrm{m}$ particle size, RS Tech, Seoul, Korea); mobile phase $\mathrm{MeCN}$ in $\mathrm{H}_{2} \mathrm{O}$ containing $0.1 \% \mathrm{HCO}_{2} \mathrm{H}$ (0-65 min: $20 \% \mathrm{MeCN}$, $65 \mathrm{~min}: 100 \% \mathrm{MeCN}$ ); flow rate: $2 \mathrm{~mL} / \mathrm{min}$ ] to give compounds 12 (phlorofucofuroeckol A, $15.0 \mathrm{mg}$ ) and $\mathbf{1 4}$ (dioxinodehydroeckol, $4.0 \mathrm{mg}$ ). Fraction F70.3 was further purified by HPLC (Optimapack $\mathrm{C}_{18}$ column $(10 \mathrm{~mm} \times 250 \mathrm{~mm}, 10 \mu \mathrm{m}$ particle size, RS Tech, Seoul, Korea); mobile phase $\mathrm{MeCN}$ in $\mathrm{H}_{2} \mathrm{O}$ containing $0.1 \% \mathrm{HCO}_{2} \mathrm{H}(0-60$ min: $30 \% \mathrm{MeCN}$, $65 \mathrm{~min}: 100 \% \mathrm{MeCN}$ ); flow rate: $2 \mathrm{~mL} / \mathrm{min}$ ) to yield compound 16 (fucofuroeckol A, $4.0 \mathrm{mg}$ ). All of the isolated materials and related information were kept in the Korea Bioactive Natural Material Bank (KBNMB).

\subsubsection{Dibenzodioxin-fucodiphloroethol (DFD) (1)}

Brown powder; $[\alpha]_{\mathrm{D}}^{20}+1.5$ (c 0.1, MeOH); UV(MeOH) $\lambda_{\max }(\log \varepsilon) 230$ (2.15); IR $v_{\max } 3863,3840$, $3734,3647,3272,2675,2348,1748,1620,1540,1508,1487,1396,1269,1198,1150,1090,1039,1024 \mathrm{~cm}^{-1}$; ${ }^{1} \mathrm{H}$ and ${ }^{13} \mathrm{C}$ NMR data $\left(800 / 200 \mathrm{MHz}\right.$; DMSO- $\left.d_{6}\right)$, see Table S3; HRFABMS $m / z$ 743. 0895 (calcd. for $[\mathrm{M}-\mathrm{H}]^{-}$, 743.0890).

\subsubsection{Dibenzodioxin-fucodiphloroeckol (DFE) (2)}

Brown powder; $[\alpha]_{\mathrm{D}}^{20}-22.7$ (c 0.1, MeOH); UV(MeOH) $\lambda_{\max }(\log \varepsilon) 230$ (2.15); IR $v_{\max }$ 3840, $3223,2348,1748,1620,1508,1474,1396,1259,1088,1039,1023,997,827 \mathrm{~cm}^{-1} ;{ }^{1} \mathrm{H}$ and ${ }^{13} \mathrm{C} \mathrm{NMR}$ data $\left(850 / 212.5 \mathrm{MHz}\right.$; DMSO- $d_{6}$ ), see Table S3; HRFABMS m/z 1113.1215 (calcd. for $[\mathrm{M}-\mathrm{H}]^{-}$, 1113.1215).

\subsection{HPLC-qTOFMS Measurement}

HPLC-qTOFMS was performed on an Agilent 6500 series instrument (Agilent technologies, USA) with a dual ESI interface at the College of Pharmacy, Seoul National University, Korea. A YMC-Triart $\mathrm{C}_{18}$ column $(150 \mathrm{~mm} \times 3.0 \mathrm{~mm}$ i.d., $5 \mu \mathrm{m})$ was used for separation. The elution gradient consisted of $\mathrm{H}_{2} \mathrm{O}(\mathrm{A}$ ) and $\mathrm{MeCN}$ (B) (both buffered with $0.01 \%$ formic acid) increased from $10 \% \mathrm{~B}$ to $60 \% \mathrm{~B}$ (for fraction EC30) and 100\% B (for fraction EC70) in $40 \mathrm{~min}(0.3 \mathrm{~mL} / \mathrm{min}$ ), where it was held in $12 \mathrm{~min}$ $(1 \mathrm{~mL} / \mathrm{min})$, returned to $10 \% \mathrm{~B}$ in $0.1 \mathrm{~min}$, and then maintained for $5 \mathrm{~min}(0.3 \mathrm{~mL} / \mathrm{min})$. Nitrogen was used as the drying gas and collision gas in the ESI source. The electrospray ion source parameters 
were as follows: drying gas flow rate, $10 \mathrm{~L} / \mathrm{min}$; heated capillary temperature, $350{ }^{\circ} \mathrm{C}$; sheath gas temperature of $350^{\circ} \mathrm{C}$ and flow of $12 \mathrm{~L} / \mathrm{min}$; nebulizer pressure, $30 \mathrm{psi}$; VCap, fragmentor, skimmer, and octopole RF peak voltages that were set at 4000, 180, 60, and $750 \mathrm{~V}$, respectively. The detection was carried out in positive and negative electrospray ionization modes, and the spectra were recorded by MS scanning in the range of $m / z$ 100-1000. The MS/MS analyses were carried out by targeted fragmentation and the collision energy was set at $20-80 \mathrm{eV}$ for fractions EC30 and EC70 and at $50 \mathrm{eV}$ for single compounds. MassHunter software version B.06.01 (Agilent Technology) was used to control the LC-MS/MS system. Version B.07.00 was used for data acquisition, analysis, and processing, including the prediction of chemical formula and exact mass calculation.

\subsection{Cell Cultures and Viruses}

MDCK cells were provided by American Type Culture Collection (ATCC, Manassas, VA 20108, USA) and cultured in Dulbecco's modified Eagle's medium (DMEM) containing 10\% FBS, 100 $\mathrm{U} / \mathrm{mL}$ penicillin, and $100 \mu \mathrm{g} / \mathrm{mL}$ streptomycin. Influenza A viruses $(\mathrm{H} 1 \mathrm{~N} 1 \mathrm{~A} / \mathrm{PR} / 8 / 34$ or H9N2 A/chicken/Korea/01210/2001) were obtained from Choong Ang Vaccine Laboratory, Korea, and they were stored at $-80^{\circ} \mathrm{C}$.

\subsection{Cytotoxicity Assay}

The cell viabilities were evaluated by a MTT (3-(4,5-dimethyl-2-thiazolyl)-2,5-diphenyl-2Htetrazolium bromide) assay. Briefly, MDCK cells were seeded in 96-well plates at $1 \times 10^{5}$ cells per well and then incubated for $24 \mathrm{~h}$. The cultures were then replaced with DMEM-free serum and treated with the test compounds for $48 \mathrm{~h}$. To avoid solvent toxicity, the final concentration of dimethyl sulfoxide (DMSO) was maintained at $0.05 \%(v / v)$. Subsequently, $20 \mu \mathrm{L}$ of a $2 \mathrm{mg} / \mathrm{mL}$ MTT solution was added to each well and the plates were incubated for $4 \mathrm{~h}$ at $37^{\circ} \mathrm{C}$. After removing the medium, the formazan crystals were dissolved with $100 \mu \mathrm{L}$ of DMSO and the absorbance was measured at $550 \mathrm{~nm}$ using a microplate reader (VersaMaxTM, Randor, PA, USA). All of the experiments were performed in triplicate. Regression analysis was applied to calculate the $50 \%$ cytotoxic concentration $\left(\mathrm{CC}_{50}\right)$.

\subsection{Cytopathic Effect (CPE) Assay}

MDCK cells were seeded onto 96-well plates and incubated for $24 \mathrm{~h}$. After washing twice with phosphate-buffered saline (PBS), the cells were infected with influenza viruses using DMEM that contained $0.15 \mu \mathrm{g} / \mathrm{mL}$ trypsin and $5 \mu \mathrm{g} / \mathrm{mL}$ BSA for $2 \mathrm{~h}$. The cells were then washed with PBS, and new media containing the fractions or test compounds at different concentrations was added. After incubation for three days at $37^{\circ} \mathrm{C}$ under a $5 \% \mathrm{CO}_{2}$ atmosphere, the medium was replaced with DMEM, $20 \mu \mathrm{L}$ of $2 \mathrm{mg} / \mathrm{mL}$ MTT was added to each well, and the plates were incubated for an additional $4 \mathrm{~h}$. The next steps followed a typical cytotoxicity assay procedure and the $50 \%$ effective concentration $\left(\mathrm{EC}_{50}\right)$ was calculated by regression analysis.

\subsection{Western Blot Analysis}

MDCK cells were grown into 6-well plates and infected with H1N1 A/PR/8/34 virus for $2 \mathrm{~h}$. The cells were then washed with PBS and the media was replaced with new media with various concentrations of the test compounds. After $24 \mathrm{~h}$ of incubation, the cells were washed with cold PBS and then lysed with $100 \mu \mathrm{L}$ of lysis buffer [50 mM Tris- $\mathrm{HCl}(\mathrm{pH} 7.6), 120 \mathrm{mM} \mathrm{NaCl}, 1 \mathrm{mM}$ EDTA, $0.5 \% \mathrm{NP}-40$, and $50 \mathrm{mM} \mathrm{NaF]}$. The supernatants were collected, and the protein concentrations were determined using a protein assay kit (Bio Rad Laboratories Inc., USA). The aliquots of the lysates were boiled for $5 \mathrm{~min}$ and loaded onto $10 \%$ or $12 \%$ SDS-polyacrylamide gels. The gels were then electrophoresed and electrotransferred to polyvinylidene fluoride membranes (PVDF $0.45 \mu \mathrm{m}$, Immobilon-P, USA). After blocking with a 5\% skim milk solution, the membranes were incubated overnight at $4{ }^{\circ} \mathrm{C}$ with primary antibodies, namely, neuraminidase (Gene Tex, San Antonio, TX, USA), hemagglutinin (Sigma, St Louis, MO, USA), or mouse monoclonal actin (Abcam, Cambridge, UK). 
After washing a few times with PBS, the membranes were incubated with secondary antibodies for $2 \mathrm{~h}$ and then detected by a chemiluminescence Western blotting detection kit (Thermo Fisher Scientific., Rockford, IL, USA) using an Image Quant ${ }^{\mathrm{TM}}$ LAS4000 imaging system.

\subsection{Immunofluorescence Assay}

The MDCK cells were maintained on sterile glass coverslips and then infected with H1N1 $\mathrm{A} / \mathrm{PR} / 8 / 34$ virus for $2 \mathrm{~h}$. After that, the cells were transferred to new media containing the test compounds at various concentrations. The cultures were incubated at $37{ }^{\circ} \mathrm{C}$ under a $5 \%$ $\mathrm{CO}_{2}$ atmosphere for $24 \mathrm{~h}$. After fixation and permeabilization, the cells were blocked with $1 \%$ bovine serum albumin (BSA) solution (Sigma, St. Louis, MO, USA) for $1 \mathrm{~h}$ and then incubated overnight with monoclonal neuraminidase antibody (Gene Tex) that was diluted 1:50 in PBS. The cells were then incubated with the secondary antibody FITC (fluorescence isothiocyanate)-conjugated goat anti-Rb IgG (Abcam, Cambridge, UK) for $1 \mathrm{~h}$, and the nuclei were stained with $500 \mathrm{nM}$ 4',6-diamidino-2-phenylindole (DAPI, Thermo Fisher Scientific, USA) solution for 5 min at room temperature. The slides were mounted with mounting medium for fluorescence (Vectashield, Vector Lab, Inc., USA). The immunofluorescence images were acquired with fluorescence microscopy (Olympus ix70 Fluorescence Microscope, Olympus Corporation, Tokyo, Japan).

\subsection{Statistical Analysis}

The results are presented as the mean \pm SD of three independent experiments. The significant differences between the groups were calculated by one-way analysis of variance (ANOVA) using Tukey's or Duncan's post hoc tests, which were conducted with SPSS Statistics 23 software (SPSS, Inc., Chicago, IL, USA). Statistical significance was accepted at ${ }^{*} p<0.05,{ }^{* *} p<0.01$, and ${ }^{* * *} p<0.001$. ImageJ software was applied for Western blot analysis.

Supplementary Materials: The following are available online at http:/ / www.mdpi.com/1660-3397/17/3/149/s1, Figure S1: HRESIMS spectrum of compound 1; Figure S2: IR spectrum of compound 1; Figure S3: ${ }^{1} \mathrm{H}$ NMR spectrum of compound $1\left(800 \mathrm{MHz}, \mathrm{DMSO}-d_{6}\right)$; Figure S4: ${ }^{13} \mathrm{C}$ NMR spectrum of compound $1(200 \mathrm{MHz}$, DMSO- $\left.d_{6}\right)$; Figure S5: HSQC spectrum of compound 1 ( $\left.800 \mathrm{MHz}, \mathrm{DMSO}-d_{6}\right)$; Figure S6: HMBC spectrum of compound $1\left(800 \mathrm{MHz}, \mathrm{DMSO}-d_{6}\right)$; Figure S7: ROESY spectrum of compound $1\left(800 \mathrm{MHz}, \mathrm{DMSO}-d_{6}\right)$; Figure S8: HRESIMS spectrum of compound 2; Figure S9: IR spectrum of compound 2; Figure S10: ${ }^{1} \mathrm{H}$ NMR spectrum of compound 2 (850 MHz, DMSO- $\left.d_{6}\right)$; Figure S11: ${ }^{13} \mathrm{C}$ NMR spectrum of compound 2 (212.5 MHz, DMSO- $\left.d_{6}\right)$; Figure S12: HSQC spectrum of compound $2\left(850 \mathrm{MHz}, \mathrm{DMSO}-d_{6}\right)$; Figure S13: HMBC spectrum of compound 2 (850 $\left.\mathrm{MHz}, \mathrm{DMSO}-d_{6}\right)$; Figure S14: ROESY spectrum of compound 2 (850 MHz, DMSO-d $d_{6}$ ); Figure S15: Relationships between ion masses $(\mathrm{m} / \mathrm{z}$ value) in negative ion mode and RMD values for compounds detected by HPLC-qTOFMS in the EC70 fraction; Figure S16: HPLC-qTOFMS measurement for twelve isolated compounds in negative ion mode at collision energy of $50 \mathrm{eV}$; Figure S17: MS/MS spectra and fragment ions analysis of isolated compounds. HPLC-qTOFMS spectroscopic data of these single compounds were measured in negative mode at collision energy of $50 \mathrm{eV}$; Figure S18: Effects of compound 11, 12, 13, and 14 on the viral protein synthesis at a concentration of 20 $\mu \mathrm{M}$; original uncropped blots; Figure S19: Inhibitory effects of compound $\mathbf{1 2}$ on the viral proteins synthesis in a concentration-dependent manner; original uncropped blots; Figure S20: (A) Key HMBC correlations of compounds 1 and 2. (B) Key ROESY correlations on 3D structure of compounds 1 and 2; Figure S21: Physicochemical properties of isolated known compounds from E. cava; Table S1: List of species in Ecklonia genus from website World Register of Marine Species (http:/ / www.marinespecies.org); Table S2: The inhibitory effects of compounds 11, 12, 13, and 14 against the $\mathrm{H} 1 \mathrm{~N} 1 \mathrm{~A} / \mathrm{PR} / 8 / 34$ virus in a cytopathic effect and cytotoxicity assays; Table S3. ${ }^{1} \mathrm{H}$ and ${ }^{13} \mathrm{C}$ NMR spectroscopic data of compounds 1 and 2 in DMSO- $d_{6}(\delta$ in ppm); Scheme S1: Extraction and fractionation procedure of E. cava.

Author Contributions: H.M.C. and T.P.D. performed phytochemical experiments and analysis experiments. T.K.Q.H. designed and performed biological experiments. H.W.K., B.W.L. and H.T.T.P. performed phytochemical experiments. T.O.C. collected and authenticated the plant. W.K.O. provided experimental ideas, designed the research and analyzed the data. W.K.O. contributed to the supervision and discussion and reviewed/edited the manuscript. All authors reviewed the manuscript.

Funding: This work was supported financially in part by grants from the Marine Biotechnology Program of the Ministry of Oceans and Fisheries (PJT200669) and the Korea Institute of Planning and Evaluation for Technology in Food, Agriculture and Forestry (IPET) through the Animal Disease Management Technology Development Program funded by the Ministry of Agriculture, Food and Rural Affairs (MAFRA) (318031031SB010). 
Conflicts of Interest: The authors declare no conflicts of interest.

\section{References}

1. Park, J.Y.; Kim, J.H.; Kwon, J.M.; Kwon, H.J.; Jeong, H.J.; Kim, Y.M.; Kim, D.; Lee, W.S.; Ryu, Y.B. Dieckol, a SARS-CoV 3CLpro inhibitor, isolated from the edible brown algae Ecklonia cava. Bioorganic. Med. Chem. 2013, 21, 3730-3737. [CrossRef] [PubMed]

2. Fujii, Y.; Tanaka, R.; Miyake, H.; Tamaru, Y.; Ueda, M.; Shibata, T. Evaluation for antioxidative properties of phlorotannins isolated from the brown alga Eisenia bicyclis, by the H-ORAC method. Food. Nutr. Sci. 2013, 4, 78-82.

3. Wang, T.; Jónsdóttir, R.; Liu, H.; Gu, L.; Kristinsson, H.G.; Raghavan, S.; Ólafsdóttir, G. Antioxidant capacities of phlorotannins extracted from the brown algae Fucus vesiculosus. J. Agric. Food Chem. 2012, 60, 5874-5883. [CrossRef] [PubMed]

4. Sugiura, Y.; Matsuda, K.; Yamada, Y.; Nishikawa, M.; Shioya, K.; Katsuzaki, H.; Imai, K.; Amano, H. Isolation of a New Anti-Allergic Phlorotannin, Phlorofucofuroeckol-B, from an Edible Brown Alga, Eisenia arborea. Biosci. Biotechnol. Biochem. 2006, 70, 2807-2811. [CrossRef] [PubMed]

5. Fukuyama, Y.; Kodama, M.; Miura, I.; Kinzyo, Z.; Kido, M.; Mori, H.; Nakayama, Y.; Takahashi, M. Structure of an anti-plasmin inhibitor, eckol, isolated from the brown alga Ecklonia kurome Okamura and inhibitory activities of its derivatives on plasma plasmin inhibitors. Chem. Pharm. Bull. 1989, 37, 349-353. [CrossRef] [PubMed]

6. Eo, H.J.; Kwon, T.H.; Park, G.H.; Song, H.M.; Lee, S.J.; Park, N.H.; Jeong, J.B. In vitro anticancer activity of phlorofucofuroeckol a via upregulation of activating transcription factor 3 against human colorectal cancer cells. Mar. Drugs 2016, 14, 69. [CrossRef] [PubMed]

7. Hong, J.H.; Son, B.S.; Kim, B.K.; Chee, H.Y.; Song, K.S.; Lee, B.H.; Shin, H.C.; Lee, K.B. Antihypertensive effect of Ecklonia cava extract. Korean J. Pharmacogn. 2006, 37, 200-205.

8. Bu, H.J.; Ham, Y.M.; Kim, J.M.; Lee, S.J.; Hyun, J.W.; Lee, N.H. Elastase and hyaluronidase inhibition activities of phlorotannins isolated from Ecklonia cava. Korean J. Pharmacogn. 2006, 37, 92-96.

9. Kwon, H.J.; Ryu, Y.B.; Kim, Y.M.; Song, N.; Kim, C.Y.; Rho, M.C.; Jeong, J.H.; Cho, K.O.; Lee, W.S.; Park, S.J. In vitro antiviral activity of phlorotannins isolated from Ecklonia cava against porcine epidemic diarrhea coronavirus infection and hemagglutination. Bioorganic Med. Chem. 2013, 21, 4706-4713. [CrossRef] [PubMed]

10. Moghadami, M. A narrative review of influenza: A seasonal and pandemic disease. Iran. J. Med. Sci. 2017, 42, 2-13. [PubMed]

11. Masters, B.R. Mandell, Douglas, and Bennett's Principles and Practice of Infectious Diseases, 8th ed.; Bennett, J.E., Dolin, R., Blaser, M.J., Eds.; Elsevier Saunders: Philadelphia, PA, USA, 2015; ISBN 13-978-1-4557-4801-3.

12. Rao, S.; Nyquist, A.C.; Stillwell, P.C. Influenza. In Kendig's Disorders of the Respiratory Tract in Children, 9th ed.; Elsevier: Amsterdam, The Netherlands, 2018; pp. 460-465.e2.

13. Pagano, M.; Castagnolo, D.; Bernardini, M.; Fallacara, A.L.; Laurenzana, I.; Deodato, D.; Kessler, U.; Pilger, B.; Stergiou, L.; Strunze, S.; et al. The fight against the influenza A virus H1N1: Synthesis, molecular modeling, and biological evaluation of benzofurazan derivatives as viral RNA polymerase inhibitors. Chem. Med. Chem. 2014, 9, 129-150. [CrossRef] [PubMed]

14. Fang, W.; Yang, Y.J.; Guo, B.L.; Cen, S. Anti-influenza triterpenoid saponins (saikosaponins) from the roots of Bupleurum marginatum var. stenophyllum. Bioorg. Med. Chem. Lett. 2017, 27, 1654-1659. [CrossRef] [PubMed]

15. Cox, N.J.; Subbarao, K. Global Epidemiology of Influenza: Past and Present. Annu. Rev. Med. 2000, 51, 407-421. [CrossRef] [PubMed]

16. Korteweg, C.; Gu, J. Pandemic influenza A (H1N1) virus infection and avian influenza A (H5N1) virus infection: A comparative analysis. Biochem. Cell Biol. 2010, 88, 575-587. [CrossRef] [PubMed]

17. Li, H.; Cao, B. Pandemic and Avian Influenza A Viruses in Humans: Epidemiology, Virology, Clinical Characteristics, and Treatment Strategy. Clin. Chest Med. 2017, 38, 59-70. [CrossRef] [PubMed]

18. Muramoto, Y.; Noda, T.; Kawakami, E.; Akkina, R.; Kawaoka, Y. Identification of novel influenza a virus proteins translated from PA mRNA. J. Virol. 2013, 87, 2455-2462. [CrossRef] [PubMed]

19. Tripathi, S.; Batra, J.; Lal, S.K. Interplay between influenza A virus and host factors: Targets for antiviral intervention. Arch. Virol. 2015, 160, 1877-1891. [CrossRef] [PubMed] 
20. FDA Influenza (flu) Antiviral Drugs and Related Information. Available online: https://www.fda.gov/ drugs/drugsafety/informationbydrugclass/ucm100228.htm (accessed on 1 March 2019).

21. Kildgaard, S.; Subko, K.; Phillips, E.; Goidts, V.; De La Cruz, M.; Díaz, C.; Gotfredsen, C.H.; Andersen, B.; Frisvad, J.C.; Nielsen, K.F.; et al. A dereplication and bioguided discovery approach to reveal new compounds from a marine-derived fungus Stilbella fimetaria. Mar. Drugs 2017, 15, 253. [CrossRef] [PubMed]

22. Sleno, L. The use of mass defect in modern mass spectrometry. J. Mass Spectrom. 2012, 47, 226-236. [CrossRef] [PubMed]

23. Ekanayaka, E.A.P.; Celiz, M.D.; Jones, A.D. Relative Mass Defect Filtering of Mass Spectra: A path to discovery of plant specialized metabolites. Plant Physiol. 2015, 167, 1221-1232. [CrossRef] [PubMed]

24. Stagliano, M.C.; DeKeyser, J.G.; Omiecinski, C.J.; Jones, D.D. Bioassay-directed fractionation for discovery of bioactive neutral lipids guided by relative mass defect filtering and multiplexed collision-induced dissociation. Rapid Commun. Mass Spectrom. 2010, 24, 3578-3584. [CrossRef] [PubMed]

25. Butler, M.S.; Fontaine, F.; Cooper, M.A. Natural product libraries: Assembly, maintenance, and screening. Planta Med. 2014, 80, 1161-1170. [CrossRef] [PubMed]

26. Abdelmohsen, U.R.; Cheng, C.; Viegelmann, C.; Zhang, T.; Grkovic, T.; Ahmed, S.; Quinn, R.J.; Hentschel, U.; Edrada-Ebel, R.A. Dereplication strategies for targeted isolation of new antitrypanosomal actinosporins a and B from a marine sponge associated-Actinokineospora sp. EG49. Mar. Drugs 2014, 12, 1220-1244. [CrossRef] [PubMed]

27. Li, Y.; Fu, X.; Duan, D.; Liu, X.; Xu, J.; Gao, X. Extraction and Identification of Phlorotannins from the Brown Alga, Sargassum fusiforme (Harvey) Setchell. Mar. Drugs 2017, 15, 49. [CrossRef] [PubMed]

28. Imbs, T.I.; Zvyagintseva, T.N. Phlorotannins are polyphenolic metabolites of brown algae. Russ. J. Mar. Biol. 2018, 44, 263-273. [CrossRef]

29. Yotsu-Yamashita, M.; Kondo, S.; Segawa, S.; Lin, Y.C.; Toyohara, H.; Ito, H.; Konoki, K.; Cho, Y.; Uchida, T. Isolation and structural determination of two novel phlorotannins from the brown alga Ecklonia kurome Okamura, and their radical scavenging activities. Mar. Drugs 2013, 11, 165-183. [CrossRef] [PubMed]

30. Kang, Y.M.; Eom, S.H.; Kim, Y.M. Protective effect of phlorotannins from Eisenia bicyclis against lipopolysaccharide-stimulated inflammation in HepG2 cells. Environ. Toxicol. Pharmacol. 2013, 35, 395-401. [CrossRef] [PubMed]

31. Li, Y.; Lee, S.H.; Le, Q.T.; Kim, M.M.; Kim, S.K. Anti-allergic effects of phlorotannins on histamine release via binding inhibition between IgE and FceRI. J. Agric. Food Chem. 2008, 56, 12073-12080. [CrossRef] [PubMed]

32. Li, Y.; Qian, Z.J.; Ryu, B.M.; Lee, S.H.; Kim, M.M.; Kim, S.K. Chemical components and its antioxidant properties in vitro: An edible marine brown alga, Ecklonia cava. Bioorg. Med. Chem. 2009, 17, 1963-1973. [CrossRef] [PubMed]

33. Yang, H.K.; Jung, M.H.; Avunje, S.; Nikapitiya, C.; Kang, S.Y.; Ryu, Y.B.; Lee, W.S.; Jung, S.J. Efficacy of algal Ecklonia cava extract against viral hemorrhagic septicemia virus (VHSV). Fish Shellfish Immunol. 2018, 72, 273-281. [CrossRef] [PubMed]

34. Kim, E.B.; Kwak, J.H. Antiviral phlorotannin from Eisenia bicyclis against human papilloma virus in vitro. Planta Med. 2015, 81, 22. [CrossRef]

35. Eom, S.H.; Moon, S.Y.; Lee, D.S.; Kim, H.J.; Park, K.; Lee, E.W.; Kim, T.H.; Chung, Y.H.; Lee, M.S.; Kim, Y.M. In vitro antiviral activity of dieckol and phlorofucofuroeckol-A isolated from edible brown alga Eisenia bicyclis against murine norovirus. Algae 2015, 30, 241-246. [CrossRef]

(C) 2019 by the authors. Licensee MDPI, Basel, Switzerland. This article is an open access article distributed under the terms and conditions of the Creative Commons Attribution (CC BY) license (http://creativecommons.org/licenses/by/4.0/). 